\title{
Observations of turbulence-induced new particle formation in the residual layer
}

\author{
B. Wehner ${ }^{1}$, H. Siebert ${ }^{1}$, A. Ansmann ${ }^{1}$, F. Ditas ${ }^{1}$, P. Seifert ${ }^{1}$, F. Stratmann ${ }^{1}$, A. Wiedensohler ${ }^{1}$, A. Apituley ${ }^{2}$, \\ R. A. Shaw ${ }^{1,3}$, H. E. Manninen ${ }^{4}$, and M. Kulmala ${ }^{4}$ \\ ${ }^{1}$ Leibniz Institute for Tropospheric Research, 04318 Leipzig, Germany \\ ${ }^{2}$ RIVM - National Institute for Public Health and the Environment, 3720 BA Bilthoven, The Netherlands \\ ${ }^{3}$ Department of Physics, Michigan Technological University, Houghton, MI 49931, USA \\ ${ }^{4}$ Department of Physics, University of Helsinki, P.O. Box 64, 00014 Helsinki, Finland
}

Received: 25 November 2009 - Published in Atmos. Chem. Phys. Discuss.: 8 January 2010

Revised: 4 May 2010 - Accepted: 4 May 2010 - Published: 7 May 2010

\begin{abstract}
Aerosol particle measurements in the atmospheric boundary layer performed by a helicopter-borne measurement payload and by a lidar system from a case study during the IMPACT field campaign in Cabauw (NL) are presented. Layers of increased number concentrations of ultrafine particles were observed in the residual layer, indicating relatively recent new-particle formation. These layers were characterized by a sub-critical Richardson number and concomitant increased turbulence. Turbulent mixing is likely to lead to local supersaturation of possible precursor gases which are essential for new particle formation. Observed peaks in the number concentrations of ultrafine particles at ground level are connected to the new particle formation in the residual layer by boundary layer development and vertical mixing.
\end{abstract}

\section{Introduction}

New particle formation (NPF) in the size range of a few nanometers in diameter, has been observed in the atmosphere at various locations: urban, remote, and arctic sites (e.g., Stanier et al., 2004; Weber et al., 1997; Wiedensohler et al., 1996). Kulmala et al. (2004) reviewed more than 100 of such experimental studies from worldwide locations concluding that NPF was found under a wide range of atmospheric conditions almost everywhere on the globe where it was looked for. Newly formed particles are too small to scatter light or act as cloud condensation nuclei. However, in polluted

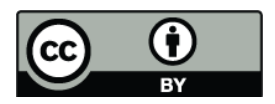

Correspondence to: $\mathrm{B}$. Wehner (birgit@tropos.de) continental regions they may grow up to $100 \mathrm{~nm}$ in diameter within a few hours and may act as cloud condensation nuclei and scatter light which may influence the regional and global climate (Laaksonen et al., 2005; Spracklen et al., 2006, 2008). Kuang et al. (2009) and Wiedensohler et al. (2009) showed for different locations that new particle formation may enhance the number of available $\mathrm{CCN}$ by an order of magnitude. Thus, being able to understand and predict NPF is a key issue in understanding and quantifying both the direct and indirect aerosol effects on climate.

However, the actual process of new particle formation, i.e. the homogeneous nucleation of new particles, around 1-2 nm in diameter, from one or more condensable species as well as different ways of heterogeneous nucleation and subsequent particle growth into detectable sizes is still not well understood. Nevertheless, it can be stated that under atmospheric conditions, sulfuric acid and water vapor are most likely the species controlling the homogeneous nucleation process (Kulmala et al., 2000), and the important contribution of organic vapors to particle growth is more or less undoubted (e.g., Marti et al., 1997; Kavouras et al., 2002; O'Dowd et al., 2002). However, we still lack basic knowledge concerning the actual mechanisms involved in NPF and their quantification.

It is still a challenging task to mechanistically understand the processes underlying NPF from atmospheric measurements. One reason being that, in the atmosphere, we are looking at the convolution of different meteorological, gas phase and particle dynamical processes making it hard to quantify the influences of a particular process. For example, if the growth of the homogeneously nucleated particles is not sufficiently fast (e.g., due the lack of precursors), the

Published by Copernicus Publications on behalf of the European Geosciences Union. 
particles coagulate with, and are removed by, the pre-existing aerosol population and, although homogeneous nucleation took place, no NPF is observed (O'Dowd et al., 2002; Kulmala et al., 2000, 2004). Furthermore, some of the observed events obviously depend on, or are even controlled by, mixing processes linking the development of the planetary boundary layer (PBL) to NPF as discussed in detail in Bigg (1997) and Nilsson et al. (2001a). However, although trying to understand mechanistically the processes underlaying NPF is somewhat awkward, trying to identify and understand the influences of a particular meteorological, gas phase or particle dynamical process on NPF seems a realistic task, and will help to make NPF more predictable.

Within the framework of this paper we deal with the influences of a meteorological process, specifically the development of the PBL, on NPF. Data concerning this topic are sparse as the majority of available NPF measurements were performed close to ground, i.e., maybe in the wrong place, and no conclusions about the influences of PBL dynamics on NPF can be given.

For a detailed investigation of the vertical variation of aerosol particles during formation events the intensive field campaign SATURN ("Strahlung, vertikaler Austausch, Turbulenz und Partikel-Neubildung"; radiation, vertical exchange, turbulence and new particle formation) was performed in 2002 (Stratmann et al., 2003). Here, increased number concentrations of ultrafine particles were observed after break-up of the nocturnal inversion within the whole mixed layer (Stratmann et al., 2003) and near the inversion correlating well with high fluctuations of the temperature and humidity caused by plumes penetrating the inversion (Siebert et al., 2004). Such penetration caused intensive mixing, which in turn apparently significantly increased nucleation and growth rates. Another analysis from the same campaign showed NPF on the lower edge of a low level jet corresponding to large gradients of temperature, humidity and $\mathrm{SO}_{2}$-concentration (Siebert et al., 2007). The main conclusion from this campaign was that NPF occurs frequently in elevated heights and different mechanisms might be involved as partly discussed in Nilsson et al. (2001a) while the horizontal extent can be up to $400 \mathrm{~km}$ (Wehner et al., 2007) in central Europe.

During the SATURN campaign NPF events in elevated heights were identified by increased number concentrations between 5 and $10 \mathrm{~nm}$, while number size distributions were not measured there. In addition it was difficult to follow the development of the planetary boundary layer, because no continuous remote sensing was available, such as a lidar.

This study presents results from measurements of the autonomous platform ACTOS (Airborne Cloud Turbulence Observations System), which was carried by a helicopter to measure meteorological, aerosol, and cloud parameters up to a height of $2000 \mathrm{~m}$ during the "Intensive Observation Period at Cabauw Tower" (IMPACT) in The Netherlands, 2008. In addition, data from a number of remote sensing instruments as well as ground-based equipment were available during that period. The presented combination of helicopter flights and lidar measurements is unique and helps to understand the potential connection between particle formation and growth and boundary layer development.

\section{Experimental}

\subsection{Measurement site CESAR in Cabauw}

The field campaign IMPACT was part of the EU-project EUCAARI (Kulmala et al., 2009) and was performed at the Cabauw Experimental Site for Atmospheric Research (CESAR, Russchenberg et al., 2005). The Cabauw site is operated by seven Dutch research institutes and represents a major scientific international site for remote sensing, atmospheric research and climate monitoring. Its main landmark is the $213 \mathrm{~m}$ high meteorological mast. The site is located $30 \mathrm{~km}$ southwest of Utrecht $\left(51^{\circ} 58.223^{\prime} \mathrm{N}, 4^{\circ} 55.575^{\prime} \mathrm{E}\right)$, a rural area in the central part of The Netherlands within Northwestern Europe. The flat terrain provides horizontally homogeneous conditions, a key prerequisite for boundary layer investigations. At the Cabauw Tower, various meteorological parameters as well as aerosol number size distributions are measured continuously. During the intensive phase of IMPACT additional aerosol characterization has been installed at the the tower as well as a variety of remote sensing instrumentation.

\subsection{Instrumentation}

This study is mainly based on measurements performed with the helicopter-borne measurement payload known as ACTOS (Airborne Cloud Turbulence Observation System). These observations are supported by continuous remotesensing measurements of the lidar CEALI (CESAR Water Vapour, Aerosol and Cloud Lidar) and aerosol measurements at $60 \mathrm{~m}$ above ground level. All systems are briefly introduced in the following subsections.

\subsubsection{The measurement platform ACTOS}

The helicopter-borne measurement payload ACTOS was used to perform temporal and spatial highly-resolved measurements in the PBL up to a height of $2000 \mathrm{~m}$ above ground. ACTOS is an autonomous system which is carried by means of a $140 \mathrm{~m}$ long rope as external cargo below a helicopter and flown with a true airspeed of about $20 \mathrm{~ms}^{-1}$ to ensure safe flights out of the helicopter's downwash (Siebert et al., 2006). The payload is equipped with fast sensors for measuring the three-dimensional wind vector, temperature, static pressure, and humidity. A state of the art navigation unit provides attitude angles, position, and velocity vector components to transfer the wind measurements into an Earthfixed coordinate system. In addition to the meteorological 
standard parameters, cloud microphysical properties such as cloud droplet sizes and number concentrations are measured during cloud conditions.

A real-time data acquisition system and independent power unit complete ACTOS. A telemetry link to the helicopter ensures online monitoring of basic parameters during the flight. One scientist is onboard to fine tune the flight pattern accordingly to the observed stratification and local situation.

A new comprehensive set of systems for physical aerosol characterization was integrated in ACTOS and is described in more detail in the following subsection.

\subsubsection{Aerosol measurements on ACTOS}

Particle number size distributions ( $6 \mathrm{~nm}$ to $2.5 \mu \mathrm{m})$ as well as the total number concentration were measured on ACTOS during IMPACT. A common inlet was used for all aerosol measurements leading the sample flow through a diffusion dryer to ensure dry measurement conditions $(<50 \%)$. A flow splitter divides the flow line into three lines for a total CPC (Condensation Particle Counter, model 3762A, TSI Inc., St. Paul, MN, USA), a SMPS (Scanning Mobility Particle Sizer) and an OPC (Optical Particle Counter, model 1.129, Grimm Aerosol Technik, Ainring, Germany). The custom-built SMPS system consists mainly of a Kr-85 Neutralizer (model 3077A, TSI Inc.), a Hauke type DMA (short version), and a CPC (model 3762A, TSI Inc.). This system was optimized in terms of weight and power consumption for operation on ACTOS. It is autonomous with regard to flow control and measurement. This SMPS measures particle number size distributions from 6 to $250 \mathrm{~nm}$ with a temporal resolution of $120 \mathrm{~s}$. The OPC determines the number size distributions in the range from $250 \mathrm{~nm}$ to $2.5 \mu \mathrm{m}$ with a temporal resolution of $1 \mathrm{~s}$. The combination of both instruments provides aerosol particle number size distributions (NSD) from $6 \mathrm{~nm}$ to $2.5 \mu \mathrm{m}$. The other CPC measures the total particle number concentration $(N)$ with $D_{p}>6 \mathrm{~nm}$ and a temporal resolution of $1 \mathrm{~s}$.

SMPS measurements were corrected for variations in the volume flow due to pressure changes during the flight and also for diffusional losses within the inlet line. Both, SMPS and OPC have been compared under different conditions with well-characterized reference-instrumentation at IfT, such as Twin Differential Mobility Particle Sizer (TDMPS). The measurements showed a good agreement within the range of measurement uncertainties.

Assuming spherical particles, surface and volume size distributions were calculated. Integration over selected size ranges gave number, surface and volume concentrations, such as $N_{(6-20 \mathrm{~nm})}$ : particle number concentration from 6 to $20 \mathrm{~nm}, S_{(80-500 \mathrm{~nm})}$ and $V_{(80-500 \mathrm{~nm})}$ : particle surface and volume concentration from $80-500 \mathrm{~nm}$, respectively.

\subsubsection{Lidar}

The lidar CAELI (CESAR Water Vapour, Aerosol and Cloud Lidar; Apituley et al., 2009) is a high-performance, multiwavelength Raman lidar, capable of providing round-theclock measurements. The instrument provides profiles of volume backscatter and extinction coefficients of aerosol particles, the depolarisation ratio, and water-vapor-to-dry-air mixing ratio. A high-power Nd:YAG laser transmits pulses at 355,532 , and $1064 \mathrm{~nm}$. Because a large telescope is essentially blind for lidar signals from close to the instrument, a second, small telescope is needed to cover the near range, in particular for measurements in the planetary boundary layer. The lidar echoes at the elastic and Raman scattered wavelengths are relayed to the photo detectors through optical fibres. To cover the lidar signal dynamic range from close to far ranges, simultaneous 12-bit analog and $250 \mathrm{MHz}$ photon counting data acquisition is used for most channels, except for the $1064 \mathrm{~nm}$ signals. Here, an avalanche photo diode is used in analog mode only. The lidar return signals strongly depend on height $z$ (in the case of a ground-based, vertically pointing lidar) and decrease with $z^{2}$. Multiplication with $z^{2}$ thus removes the height dependence. In this way, the rangecorrected signals (Fig. 1) are obtained. Range-corrected signals at $1064 \mathrm{~nm}$ are fully dominated by particle backscatter and are therefore well-suited to display layering structure and dynamics.

\subsubsection{Aerosol measurements at ground}

The "Neutral cluster and Air Ion Spectrometer" (NAIS) is capable of measuring mobility distributions of sub- $3 \mathrm{~nm}$ neutral and charged aerosol particles and clusters (Kulmala et al., 2007 ) in the mobility diameter range of $0.8-40 \mathrm{~nm}$. Controlled charging together with the electrostatic filtering enables it to measure also the neutral aerosol particles. Mobility distribution of corona charger ions sets the lowest detection limit for NAIS in neutral particle mode close to $2 \mathrm{~nm}$. The NAIS measurement principle is based on unipolar charging of the sampled particles and their subsequent detection with an electrical mobility analyzer. The NAIS measures ion and particle number distribution in 21 size fractions with 5minute time resolution to optimize sensitivity and signal-tonoise ratio. The NAIS is developed from the Air Ion Spectrometer (AIS, Mirme et al., 2007). The instrument is described in more detail by Manninen et al. (2009). The NAIS used here took part in a calibration and inter-comparison workshop before and after the field measurements and agreed sufficient with other instruments (Asmi et al., 2009). 


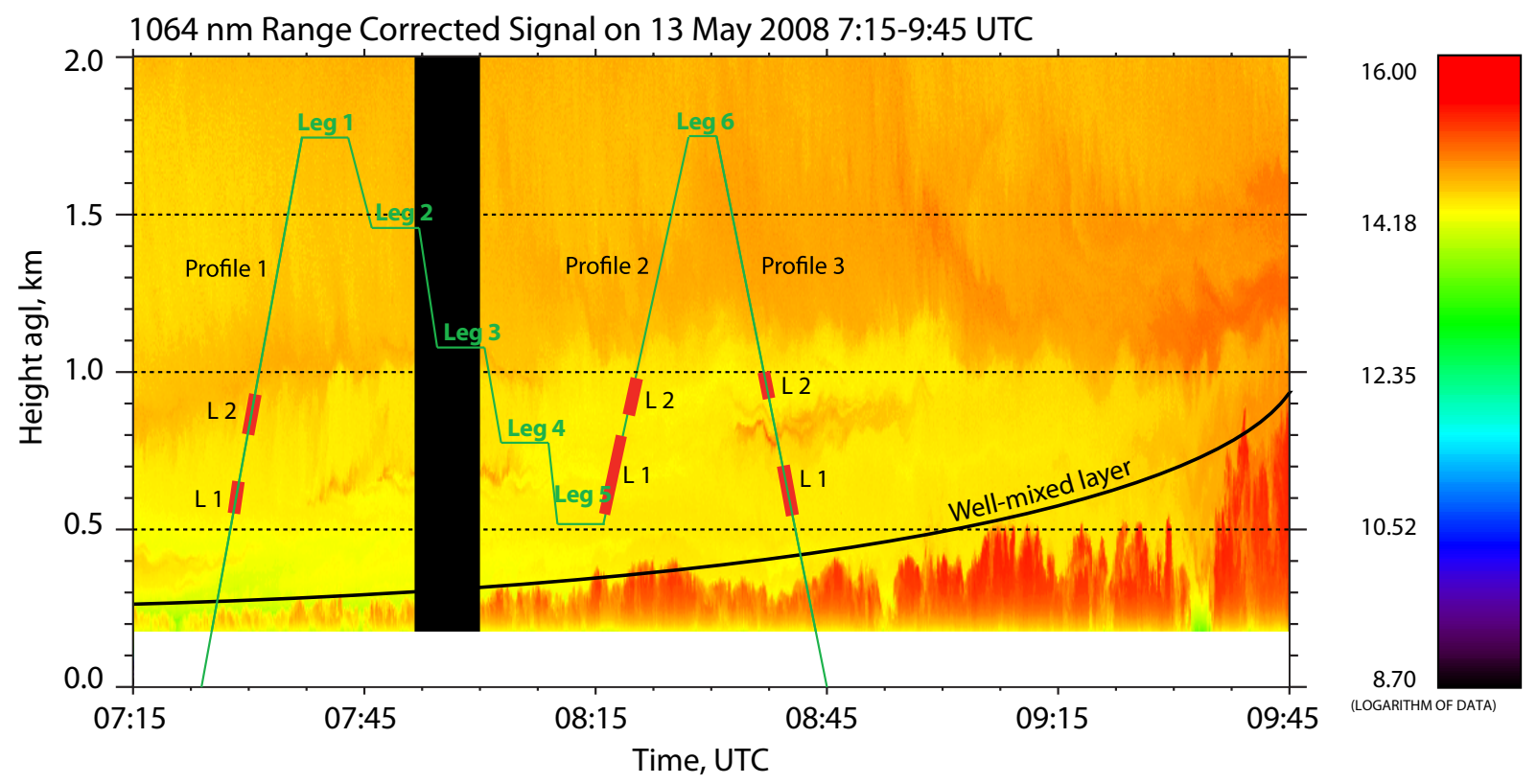

Fig. 1. Evolution of the boundary layer and lofted aerosol layers on 13 May 2008, from 07:15-09:45 UTC in terms of the range-corrected $1064 \mathrm{~nm}$ lidar signal. The vertical resolution is $7.5 \mathrm{~m}$ and the temporal resolution $10 \mathrm{~s}$. Lidar signals are not trustworthy below $150 \mathrm{~m}$ because of the incomplete transmitter-receiver overlap. The ACTOS-flight pattern is marked by the green line, the profiles and horizontal legs are labeled accordingly. L1 and L2 indicate layers with significantly increased particle number concentrations (discussed later in more detail).

Table 1. Main characteristics of vertical profiles and height of the two layers L1 and L2.

\begin{tabular}{cllll}
\hline section name & height $[\mathrm{m}]$ & time [UTC] & Layer L1 & Layer L2 \\
\hline Profile 1 & $0-1750$ & $07: 26-07: 36$ & $550-650 \mathrm{~m}$ & $800-930 \mathrm{~m}$ \\
Profile 2 & $500-1750$ & $08: 17-08: 26$ & $550-800 \mathrm{~m}$ & $850-980 \mathrm{~m}$ \\
Profile 3 & $1750-0$ & $08: 29-08: 44$ & $550-700 \mathrm{~m}$ & $900-1000 \mathrm{~m}$ \\
\hline
\end{tabular}

\section{Measurements and results}

\subsection{Measurements}

The IMPACT campaign lasted from 1 to 31 May; ACTOS flights were performed in the period from 7 to 24 May. Altogether, 12 helicopter flights were performed within a radius of 5 nautical miles around Cabauw tower.

Here, the observations performed on 13 May are analyzed. Two measurement flights are available. The morning flight from 07:26-08:44 UTC consisted of three vertical profiles and six horizontal legs at different heights (cf. Fig. 1). A second flight was performed on this day from 10:40 to 11:43 UTC, but new particle formation was not observed. Therefore the second flight is not discussed here.

The length of horizontal flight legs was at least $5 \mathrm{~min}$ (e.g., $6 \mathrm{~km})$ to ensure at least two complete scans of the particle number size distribution. Mean characteristics of the individual profiles and horizontal flight legs are given in Tables 1 and 2 .
The flight data are supported by the continuously running lidar CAELI and the NAIS system installed on the Cabauw Tower in about $60 \mathrm{~m}$ above ground level.

\subsection{Meteorological situation}

On 13 May 2008, the weather situation was dominated by a high pressure system over central and eastern Europe. This led to a period of sunny weather with some cumulus formation around noon. Air temperatures at the ground ranged from $13^{\circ} \mathrm{C}$ in the early morning to $24^{\circ} \mathrm{C}$ in the afternoon. Polluted air masses were advected from central Europe to the field site, the wind direction was northeast to east. Due to cloud-free conditions during night an undisturbed boundary layer development (e.g., Stull, 1988) was observed throughout the morning.

The evolution of the aerosol layers (developing convective boundary layer at ground and residual layer on top) in the morning of 13 May is presented in Fig. 1. This figure shows the time series of the backscattered lidar signal 
Table 2. Mean characteristics of horizontal flight legs 1-6.

\begin{tabular}{ccccccccc}
\hline $\begin{array}{c}\text { Leg } \\
\text { No. }\end{array}$ & $\begin{array}{c}\text { height } \\
{[\mathrm{m}]}\end{array}$ & $\begin{array}{c}T \\
{\left[{ }^{\circ} \mathrm{C}\right]}\end{array}$ & $\begin{array}{c}r H \\
{[\%]}\end{array}$ & $\begin{array}{c}m \\
{\left[\mathrm{~g} \mathrm{~kg}^{-1}\right]}\end{array}$ & $\begin{array}{c}N \\
{\left[\mathrm{~cm}^{-3}\right]}\end{array}$ & $\begin{array}{c}N_{(6-20 \mathrm{~nm})} \\
{\left[\mathrm{cm}^{-3}\right]}\end{array}$ & $\begin{array}{c}S_{(80-500 \mathrm{~nm})} \\
{\left[\mu \mathrm{m}^{2} \mathrm{~cm}^{-3}\right]}\end{array}$ & $\begin{array}{c}V_{(80-500 \mathrm{~nm})} \\
{\left[\mu \mathrm{m}^{3} \mathrm{~cm}^{-3}\right]}\end{array}$ \\
\hline Leg 1 & 1750 & 6.8 & 54 & 3.97 & 1280 & 9 & 132 & 5.2 \\
Leg 2 & 1440 & 9.8 & 48 & 4.22 & 1410 & 14 & 152 & 5.8 \\
Leg 3 & 1070 & 13.0 & 43 & 4.47 & 1950 & 114 & 132 & 4.8 \\
Leg 4 & 770 & 15.9 & 36 & 4.25 & 8120 & 6270 & 134 & 4.8 \\
Leg 5 & 460 & 18.5 & 32 & 4.26 & 2406 & 28 & 132 & 4.6 \\
Leg 6 & 1750 & 6.8 & 55 & 4.13 & 1250 & 9 & 130 & 5.1 \\
\hline
\end{tabular}

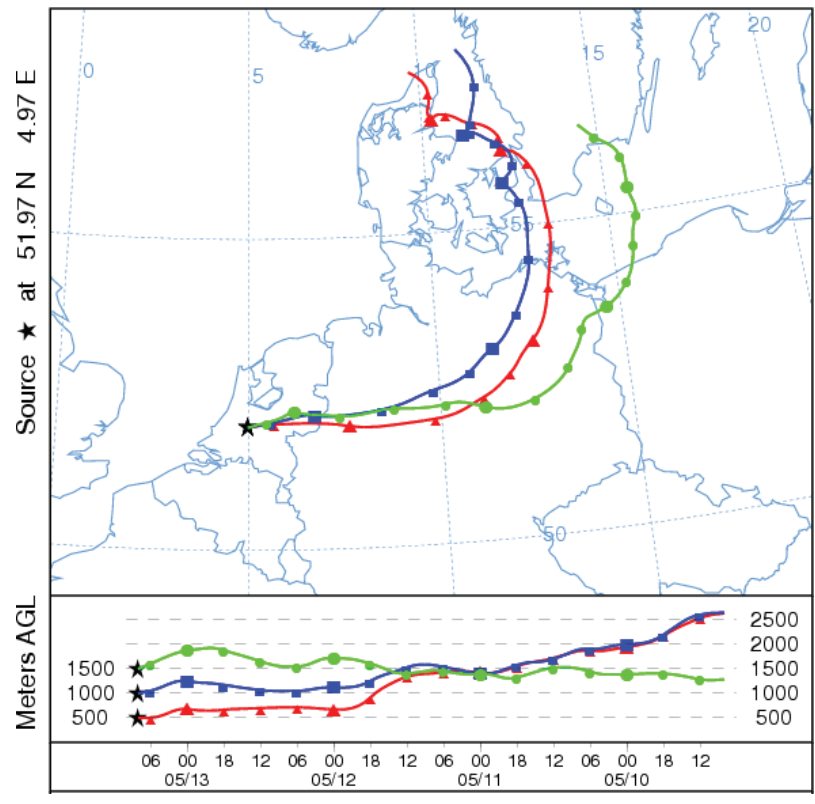

Fig. 2. 96h-backtrajectories arriving on 13 May 2008 at 08:00 UTC at heights of 500,1000, and $1500 \mathrm{~m}$ over Cabauw calculated by HYSPLIT model.

at $1064 \mathrm{~nm}$ below $2000 \mathrm{~m}$ between 07:15 and 09:45 UTC. This period includes the first ACTOS-flight. The flight pattern is illustrated in the figure. Sunrise was at 03:50 UTC. The top of the convectively active boundary layer was around $220 \mathrm{~m}$ at 07:15 UTC and increased to $500 \mathrm{~m}$ two hours later. After 09:35 UTC, the boundary layer was well-mixed so that wave-structured layers as found from 07:40-08:10 UTC (around $700 \mathrm{~m}$ height) and from 08:40-09:00 UTC (800$900 \mathrm{~m}$ height) are no longer detected. Note that the lidar signal strength increased above $1000 \mathrm{~m}$ height (above the local residual layer) caused by the advection of aged anthropogenic haze from the European continent to the east. According to the lidar observations, the continental aerosol layer reached to $3 \mathrm{~km}$ height on that day.

In order to investigate this aerosol layer, backward trajectories were calculated using the NOAA "On-line Trans- port and Dispersion Model" HYSPLIT (Draxler and Rolph, 2003). Figure 2 shows those arriving at Cabauw on 13 May 08:00 UTC in different heights: 500, 1000, and $1500 \mathrm{~m}$. The backward trajectories indicate that the air masses over Cabauw spent the past two days over continental areas of mainly Germany. They passed polluted areas such as the "Ruhr"-area in western Germany. The high backscatter signal above $1000 \mathrm{~m}$ was probably caused by aged aerosol particles from anthropogenic sources. Due to effective convection over continental areas they were lifted upwards into these heights and transported horizontally without significant removal processes. Central Europe was influenced by high pressure during these days and no rain was observed along the trajectories.

\subsection{Vertical profiles, stratification, and turbulent layers}

One unique aspect of these observations was the high resolution of the vertical profiles of thermodynamic, turbulence, and aerosol properties. The purpose of this section is to provide a detailed view of that structure and therefore illustrate the kind of vertical heterogeneity that may contribute to new particle formation. Vertical profiles from ground to the maximum height were always flown in the beginning and at the end of of each measurement flight. This was done in order to determine the development of the PBL stratification but also to define layers of particular interest in which horizontal legs had to be flown after the first profile.

Figure 3 shows selected state parameters measured by ACTOS during the first ascent after take off at 07:22 UTC on 13 May. The stratification of the PBL is described by the vertical gradient of the potential temperature $\Theta$. During night time, a strong temperature inversion $\left(\partial_{z} \Theta>0\right)$ had developed up to a height of $300 \mathrm{~m}$. Due to surface heating, a shallow $\approx$ $50 \mathrm{~m}$ thick unstable surface layer $\left(\partial_{z} \Theta<0\right)$ existed above ground. This layer was followed by a $150 \mathrm{~m}$ thick wellmixed layer (neutrally stratified with $\partial_{z} \Theta \approx 0$ ). Above the inversion, the temperature gradient was gradually decreasing (but still positive) up to a height of about $500 \mathrm{~m}$ followed by an almost neutrally stratified layer with $\partial_{z} \Theta=0$. A similar structure was observed in the profile of the water vapor mixing ratio $m$ with a well-mixed layer up to $200 \mathrm{~m}$ followed 


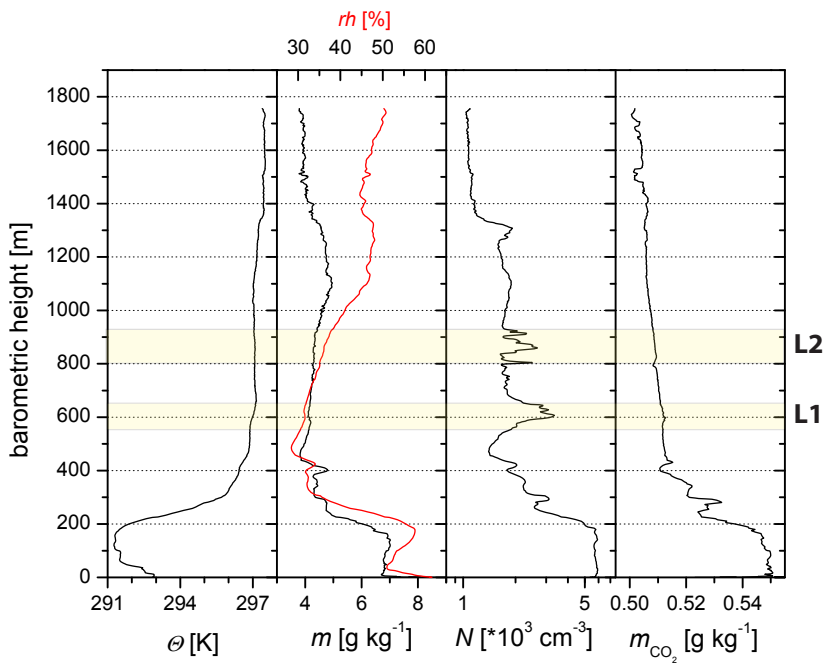

Fig. 3. Vertical profiles of potential temperature $\Theta$, relative humidity $r h$, water vapor mixing ratio $m$, particle number concentration $N$, and mixing ratio of $\mathrm{CO}_{2}$. This profile was measured during the first ascent after take-off (profile 1) on 13 May 2008. Shaded regions L1 and L2 indicate layers with enhanced particle number concentration.

by a gradual decrease of $m$ and nearly height-constant values above $500 \mathrm{~m}$. A slight increase of $m$ with a local maximum at around $1100 \mathrm{~m}$ is obvious. The profile of the $\mathrm{CO}_{2}$ mixing ratio $\left(m_{\mathrm{CO}_{2}}\right)$ shows a similar behavior as the one for $m$. Due to technical reasons, no wind data are available for the first ascent.

The profile of the aerosol particle number concentration $N$ showed a different behavior compared with the mixing ratios $m$ and $m_{\mathrm{CO}_{2}}$. Whereas in the well-mixed layer (the lowermost $200 \mathrm{~m}) N$ was height-constant with concentrations of $N \approx 6 \times 10^{3} \mathrm{~cm}^{-3}$, above the inversion the concentration decreased significantly but indicates much more variability compared to the other parameters. The most obvious features are two layers with local maxima where the concentration increased by a factor of 2 to 3 (layers are subjectively indicated as shaded areas L1 and L2 in Fig. 3). The location of these layers in all profiles is given in Table 1. A third local maximum of $N$ at $1300 \mathrm{~m}$ was topped by a small temperature inversion at $1350 \mathrm{~m}$, above this inversion there was a general decrease in $N$ to a regional tropospheric background value.

About one hour after take-off and after sampling during different legs at constant heights (which are discussed in Sec. 3.4) two further vertical profiles were flown. These measurements are shown in Fig. 4. Profile 2 was sampled during an ascent from 500 to $1750 \mathrm{~m}$. After a short horizontal leg at maximum height the final descent (profile 3) was performed from $1750 \mathrm{~m}$ to ground (cf. flight pattern in Fig. 1).

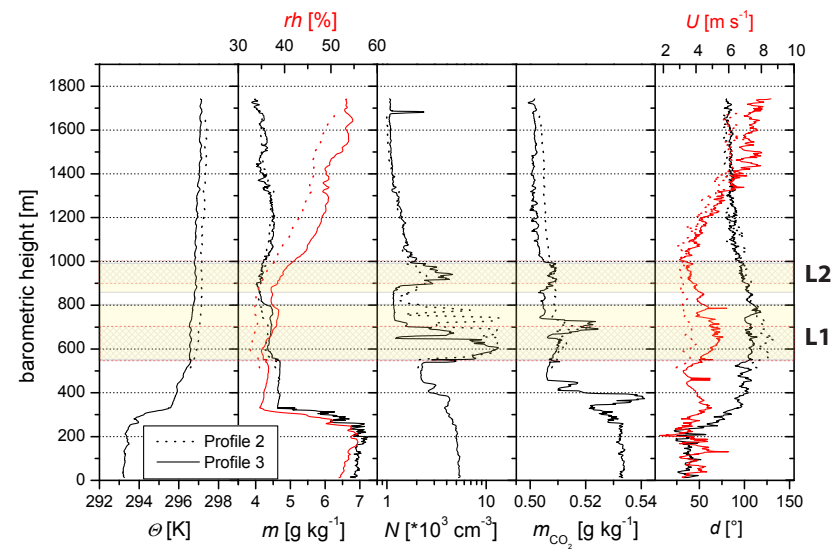

Fig. 4. Vertical profiles 2 and 3 (see Fig. 1) of the same parameters as shown in Fig. 3 but measured about one hour after the first profile. For this profiles, also mean wind speed $U$ and direction $d$ were available.

In the meantime, a well-mixed layer from the surface up to about $280 \mathrm{~m}$ had developed with nearly constant profiles of all measured parameters. The lidar backscatter indicate plumes from the well-mixed layer up to $300-400 \mathrm{~m}$ height to this time (see Fig. 1). The top of the first strong inversion was around $330 \mathrm{~m}$ followed by a second slightly stable stratified layer. This second layer reached to $550 \mathrm{~m}$ followed by a nearly neutrally stratified atmosphere. There were no significant differences between profile 2 and 3 for $\Theta$ and $m$.

Again, the aerosol profiles showed a different structure compared to the thermodynamic parameters $\Theta$ and $m$. Above the well-mixed layer with $N \approx 5-6 \times 10^{3} \mathrm{~cm}^{-3}$, a slight decrease to values close to $2 \times 10^{3} \mathrm{~cm}^{-3}$ around the inversion was observed followed by a strong increase with maximum values of $N \approx 12 \times 10^{3} \mathrm{~cm}^{-3}$ in distinct layers between 550 and $1000 \mathrm{~m}$, i.e., within the neutrally stratified region. Within this altitude range, $N$ varied between the maximum value and much lower background values which indicates strong mixing events. Compared to the first profile, the maximum particle number concentrations were nearly doubled. The lower boundaries of theses layers were nearly height-constant and the upper boundary is slightly increased from 900 to $1000 \mathrm{~m}$. Significant changes in the mean vertical gradients of the thermodynamic parameters around $1000 \mathrm{~m}$ were not observed during this period (08:15-08:45 UTC). Above the layer with high $N$, a region with nearly linear increasing horizontal wind speed $\partial_{z} U>0$ was observed whereas the wind direction did not show a noticeable change. Changing advection characteristics with height are usually associated with changing air mass characteristics (gas species, aerosol properties, etc.). The continous lidar observations in Fig. 1 reveal coherent wavelike structures of enhanced backscatter between 700 and $900 \mathrm{~m}$ in the time period from 07:30-09:00 UTC. These features also indicate a complex stratification of different air 
masses with different aerosol particle and precursor gas concentrations.

Aerosol layers detected by ACTOS occurred in a height range of inhomogenous backscatter as observed with the Raman lidar CAELI (cf. Fig. 1). The lower boundary of the more heavily particle-laden layer increases during the day from $800 \mathrm{~m}$ at 07:15 UTC to $1100 \mathrm{~m}$ at 09:00. This corresponds to the upper boundary of the layer with increased values of $N$ (L2) which increased from $900 \mathrm{~m}$ during profile 1 to $1000 \mathrm{~m}$ during profile 3 . It should be emphasized that lidar backscatter signals will not be well correlated with the total particle number concentration because the signal strength is mainly controlled by backscattering of accumulation and coarse mode particles. Signal strength also sensitively depends on relative humidity (via particle growth) and increases with increasing relative humidity, as is obviously the case here above $1000 \mathrm{~m}$ height. Furthermore, the ACTOS observations were not taken side by side with the lidar beam but within about a $5-\mathrm{km}$ radius.

Summarizing, distinct regions with increased $N$ in the residual layer were found during all three profiles but the highest values during profiles 2 and 3 . The largest vertical extension of the layer with enhanced particle concentration was measured during profile 2 from 550 to $800 \mathrm{~m}$. In all profiles a second region of increased $N$ was observed around $900 \mathrm{~m}$ but with lower maximum concentrations. The structure with two local maxima of $N$ was relatively stable in time and was observed in the first profile as well as in the two profiles about one hour later. From the vertical profiles and the stratification we hypothesize that the maxima in $N$ are caused by locally restricted new particle formation (NPF) events at those heights including horizontal transport, rather than a result of vertical transport or advection of particle-laden layers.

In order to prove this assumption, particle number size distributions measured during horizontal flight legs will be analyzed in the following section.

\subsection{Horizontal legs}

Horizontal flight legs were flown at 5 different heights between 500 and $1800 \mathrm{~m}$ (cf. Fig. 1). The measurement height during these legs was stable within $\pm 15 \mathrm{~m}$. Mean characteristics of these flight legs are given in Table 2. Note that surface area concentration $S$ shows relatively high values within all flight legs and $N_{(6-20 \mathrm{~nm})}$ varies over three orders of magnitude. During periods with relatively homogeneous particle number concentrations during the horizontal flight legs, robust estimates of particle number size distributions (NSD) are possible. Typically, 2-3 NSDs have been measured during each leg, averaged NSDs are shown in Fig. 5 for each horizontal leg. Significant variations in the nucleation and also in the Aitken mode are found for the different measurement heights. With increasing diameters differences in the number concentration become less obvious and were not significant.

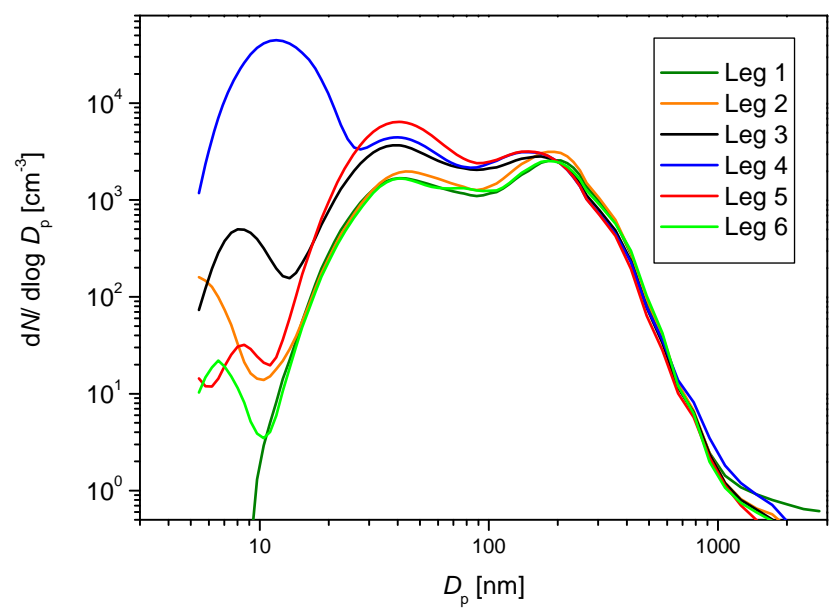

Fig. 5. Mean number size distributions measured during horizontal flight legs 1 to 6 .

Leg 1 and 6 were flown at the same height at $1750 \mathrm{~m}$ and show the lowest particle number concentrations in the Aitken mode. Their maximum is found in the accumulation mode around $200 \mathrm{~nm}$ diameter. Leg $2(1440 \mathrm{~m})$ shows very similar characteristics as leg 1 and 6 as well as a slight increase in the particle number concentration in the diameter range less than $10 \mathrm{~nm}$ which may indicate the top of the height range of major NPF. However, the uncertainty in the observations for diameters below $20 \mathrm{~nm}$ is high, mainly due to very low counting statistics and differences in $d N / d \log D_{p}<100 \mathrm{~cm}^{-3}$ are not significant for diameters below $20 \mathrm{~nm}$. In legs 3 and 4 the concentration in the accumulation mode is similar to the other legs whereas the number concentration in the Aitken mode is increased compared to the higher levels. In addition, leg 4 shows a clearly developed nucleation mode with a maximum around $10 \mathrm{~nm}$. The corresponding measurement height level $(770 \mathrm{~m})$ is in the region of increased $N$ in profile 2 (upper part of L1) which was flown less than 10 min after leg 4. Leg $5(460 \mathrm{~m})$ was below the layer of increased number concentrations and shows a much lower concentration in the nucleation mode. From the size distribution measurements during horizontal legs we can conclude that the high particle number concentrations between 550 and $800 \mathrm{~m}$ are caused by particles in the nucleation mode range, i.e. particles which have been formed by nucleation recently and grew to around $10 \mathrm{~nm}$.

As a next step, possible correlations between $N$ and other thermodynamic and dynamic parameters are analyzed. Figure 6 shows time series of vertical wind speed $w$, humidity (mixing ratio $m$ and relative humidity $r h$ ), absolute $\mathrm{CO}_{2}$ concentration and temperature $T$ during leg 4 sampled at $770 \mathrm{~m}$, which showed high concentrations of particles with diameter below $20 \mathrm{~nm}$. As an indicator for new-particle formation, $N$ is displayed in all plots for better comparison with other 


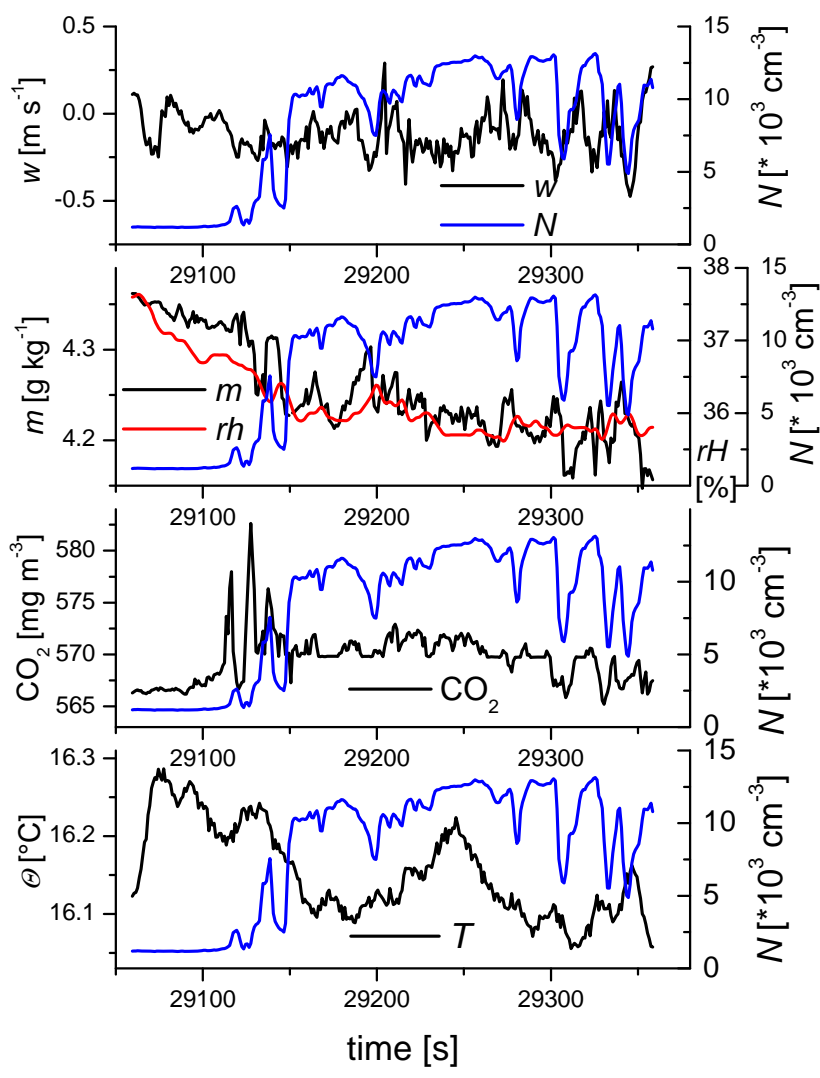

Fig. 6. Time series of vertical wind speed $w$, water vapor mixing ratio $m$, mixing ratio of $\mathrm{CO}_{2}$, and temperature $T$ measured during the horizontal leg 4 in a height of $770 \mathrm{~m}$. The particle number concentration $N$ is given for reference.

parameters (see blue curve in Fig. 6). The variation of the vertical wind speed is in the range of $\pm 0.5 \mathrm{~m} \mathrm{~s}^{-1}$ and shows slightly positive correlation with $N$. Periods with an upward flow are typically followed by an increase in $N$ with a slight time shift of 2 to $4 \mathrm{~s}$ while $2 \mathrm{~s}$ are caused by the response time of the CPC together with the residence time within the inlet line. From the vertical profiles (cf. Fig. 4) we know that leg 4 was at the upper edge of the section with NPF, thus higher concentrations of small particles were connected with a wind from below. However, the vertical wind fluctuations are typically weak in the residual layer and significant vertical transport of particles is supposed to play a minor role. Due to small spatial gradients, the fluctuations of the thermodynamic parameters $(T, m$, and $r h)$ are also small compared to the one of e.g., the well-mixed boundary layer. For example, the total ranges of observed temperatures during this leg are only $0.2 \mathrm{~K}$ and $0.2 \mathrm{~g} \mathrm{~kg}^{-1}$, respectively. With such small variation possible correlations have to be interpreted with care.

The second plot of Fig. 6 indicates a slight negative correlation between $m$ and $N$ (note again the slight time shift due to the low response time of the $\mathrm{CPC}$ ), this correlation is even less obvious in $r h$. Thus, the air with newly formed particles contains a slightly lower water vapor mixing ratio compared to the air mass with lower particle concentration.

There is no direct correlation at all between $\mathrm{CO}_{2}$ and $N$. The only interesting feature is a region of high fluctuations in $\mathrm{CO}_{2}$ before $N$ increases. In that region, $\mathrm{CO}_{2}$ concentrations are found to be higher then everywhere else during this leg. A similar effect was found in the last profile (cf., Fig 4) where an absolute maximum of $\mathrm{CO}_{2}$ for the profile was found just below the temperature inversion and the same at the top of the L2 layer of the same profile. The lowest plot shows the temperature $T$ which is higher in the first part of the leg (low $N$ ) and decreases on average with increasing $N$, but a correlation between smaller structures cannot be observed at all.

\section{Discussion}

From the previous analysis, the resulting question remains: "What are the dynamic and thermodynamic conditions that make the two identified layers favorable for NPF?".

From the analysis above we cannot explain the occurrence of the two layers with high particle number concentration. However, it is well known (e.g., Stull, 1988; Wyngaard, 1992) that sheets or layers with increased turbulence are frequently observed in the residual layer. Furthermore, turbulence and non-linear mixing of thermodynamic variables is discussed as one possible process which could lead to favorable conditions (e.g., supersaturation of precursor gases) for NPF (Bigg , 1997; Nilsson et al., 2001a). Such turbulent layers could develop when the ratio between the damping effect of the temperature inversion $\left(\partial_{z} \Theta\right)$ and the mean wind shear $\left(\partial_{z} U\right)$ is below a certain threshold. This is described by the gradient Richardson number Ri defined as:

$\mathrm{Ri}=\frac{\bar{\Theta}}{g} \frac{\partial_{z} \bar{\Theta}}{\left(\partial_{z} \bar{U}\right)^{2}}$,

where $g$ is the acceleration due to gravity, and an barred symbols denote averaged values. A critical value $\mathrm{Ri}_{c} \approx 0.25 \mathrm{di}$ vides the $\mathrm{Ri}$ number space into two regimes, for $\mathrm{Ri}<\mathrm{Ri}_{c}$ turbulence can develop since shear dominates over the damping influence of the temperature inversion. For $\mathrm{Ri}>\mathrm{Ri}_{c}$, the temperature inversion is dominant and turbulent fluctuations are suppressed. Figure 7 shows the smoothed profiles for the last descent of $U$ and $\Theta$ (same profiles as shown in Fig. 4 but smoothed by a running average with a height interval of $\approx 5 \mathrm{~m}$ ) and $\mathrm{Ri}$ (right panel) as defined by Eq. (1). The critical value $\mathrm{Ri}_{c}$ and the two layers with increased particle number concentration (L1 and L2) are plotted as reference. First of all, both layers (L1 and L2) are nearly adiabatically stratified $\left(\partial_{z} \bar{\Theta} \approx 0\right)$ and wind shear $\left(\partial_{z} \bar{U}\right)$ is present. The resulting $\mathrm{Ri}$ profile suggests that in both layers shear-induced turbulence is likely to develop. 


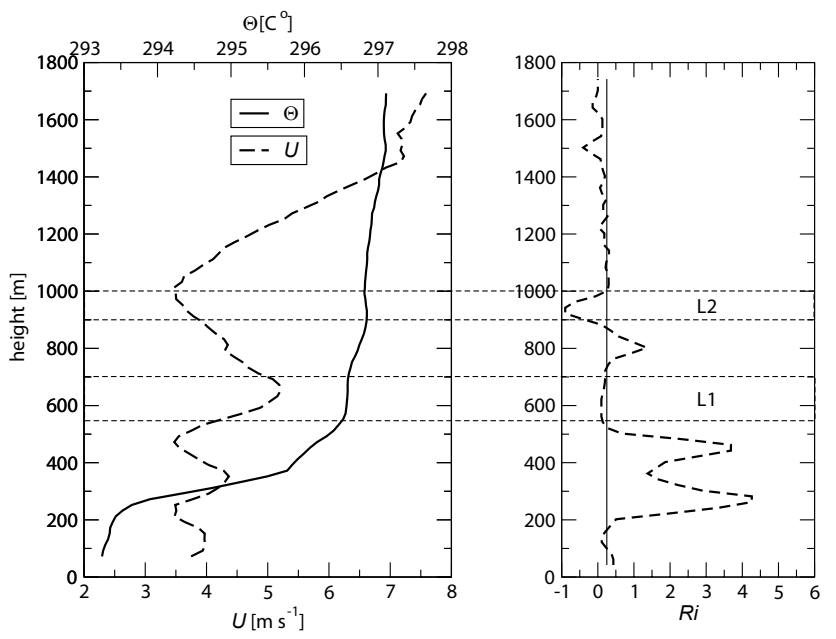

Fig. 7. Vertical profiles of smoothed $\Theta$ and $U$ (left panel) from which vertical gradients are estimated. The right panel shows the gradient Richardson number. The vertical line at $\mathrm{Ri}=0.25$ indicates the critical value, for $\mathrm{Ri}<0.25$ turbulence can develop whereas for $\mathrm{Ri}>0.25$ the damping effect of the temperature inversion becomes dominant.

As a next step, we analyze the turbulence structure by means of local energy dissipation $\varepsilon_{\tau}$. Here, $\varepsilon_{\tau}$ is derived from so-called second-order structure functions $S^{(2)}$ estimated from short, non-overlapping, subrecords of length $\tau=2 \mathrm{~s}$. Since classical Kolmogorov scaling yields $S^{(2)} \sim$ $C^{2} t^{2 / 3}$ with $C^{2}=2 \varepsilon^{2 / 3}$ the dissipation can be determined from the structure function magnitude (see Siebert et al., 2006b, and references therein for more details on this method). Figure 8 shows the profiles of $\varepsilon_{\tau}$ taken during the first ascent (profile 1, left panel) and the last descent (profile 2 , right panel); the particle number concentration $N$ is plotted and the two layers L1 and L2 are marked for comparison.

Both $\varepsilon_{\tau}$ profiles show comparably high values in the highly turbulent, well-mixed layer where production of turbulent kinetic energy due to convection is already dominant. Note that production of turbulent kinetic energy necessarily means also high energy dissipation due to the classical picture of an energy cascade. Above the well-mixed layer, the damping influence of the temperature inversion $\left(\mathrm{Ri}>\mathrm{Ri}_{c}\right)$ increases which results in decreasing turbulence. In the last profile this decrease is almost three orders of magnitude. In the residual layer - the region with the two layers (L1 and L2) with increased particle number concentration - we observe a different behavior of $\varepsilon_{\tau}$ during the two profiles. During profile $1, \varepsilon_{\tau}$ shows a local maximum in both layers L1 and L2 with an increase by a factor of NSD2 indicating a more turbulent layer compared to the background. Even though this increase of turbulence is not very strong, the qualitative correlation of increased $\varepsilon_{\tau}$ and increased $N$ in L1 and L2 is obvious. For the last descent, the profile of $\varepsilon_{\tau}$ in the region of

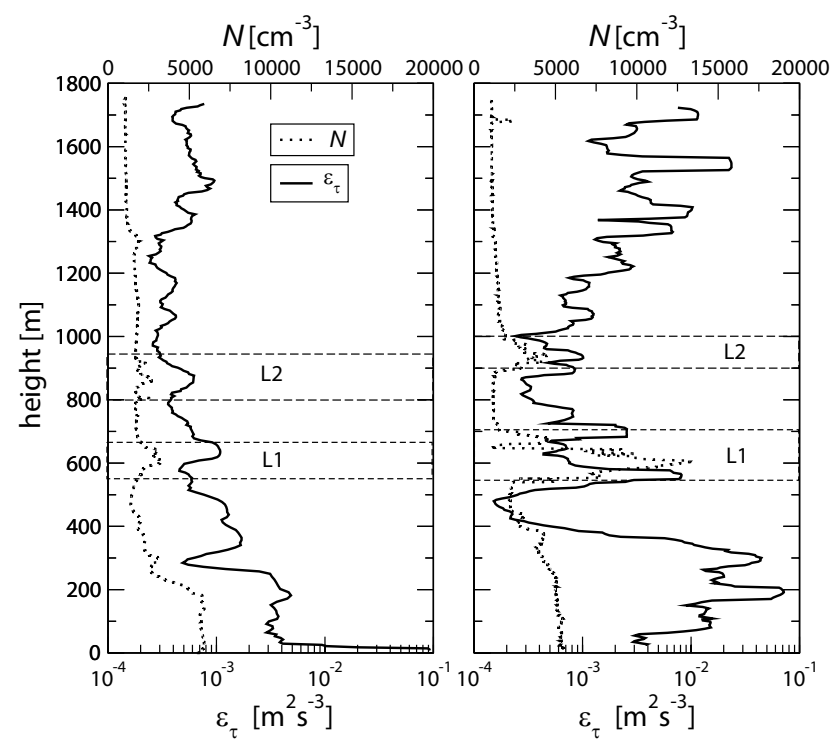

Fig. 8. Vertical profiles of the local energy dissipation rate $\varepsilon_{\tau}$ (solid lines) and the particle number concentration $N$ (dotted lines) for profile 1 (left) and profile 3 (right). Energy dissipation is estimated from second-order structure functions over non-overlapping sub-records of $\tau=2 \mathrm{~s}$.

new-particle formation gives a slightly different picture. In particular for the region L1, an increase of $\varepsilon_{\tau}$ of nearly two orders of magnitude was measured. But in contrast to the first profile, the maximum values are shifted more to the upper and lower boundaries of L1. For L2, the picture is quite similar but much less pronounced. The increase of $\varepsilon_{\tau}$ above and below L1 is obviously due to shear-induced turbulence (cf., Fig. 4 and 7). The same arguments might be valid for the first profile but cannot be proven due to the lack of the mean horizontal wind speed data for this profile.

There are several arguments that the observed particles have been nucleated and grown into the observed size range within the two distinct layers. From our observations it is not possible to determine the exact age of the small particles but typically the growth rate can be estimated to a few $\mathrm{nm}$ per hour (Kulmala et al., 2004) which results in a particle age of one hour or for more polluted conditions as short as a few minutes. This can also be taken as an indication supporting our hypothesis that these particles were formed inside these layers. The only parameter which gives us a consistent picture is the local turbulence structure described by $\varepsilon_{\tau}$. For the first profile, both particle layers are more turbulent compared with the surrounding regions and the maximum values of $\varepsilon_{\tau}$ are found in the core of the layers. The last profile shows that the mixing in the core of the layers is decreasing but strong turbulent mixing occurs at the boundaries of the particle layers leading to an increase of the vertical extent of the turbulent layers. Due to the lack of effective vertical mixing in 


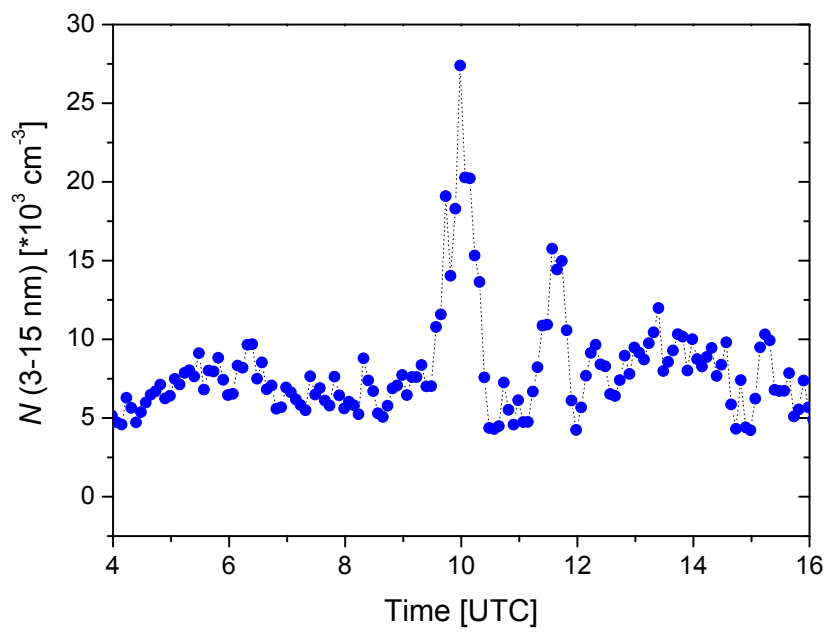

Fig. 9. Diurnal variation of number concentration of total particles in the size range 3-15 nm measured with the NAIS on 13 May 2008 at Cabauw. The measurements were taken in a height of $60 \mathrm{~m}$ above ground at the Cabauw tower.

that region these layers are quite stable and conserved over several hours with its individual mean properties. We can only speculate as to whether the turbulent mixing in these layers leads to favorable conditions (e.g., supersaturation of precursor gases) for the nucleation event.

Another key question in this context is the relation between our observations of new particle formation in the residual layer and ground-based observations.

The total number concentration measured at ground level by NAIS (Fig. 9) shows a rapid increase for particles between 3 and $15 \mathrm{~nm}$ starting at 09:45 UTC. A few minutes before (NSD 09:35 UTC), the onset of thorough mixing up to a height of about $800 \mathrm{~m}$ was observed by the lidar (see Fig. 1). Therefore, it is natural to speculate that those particles observed in leg 4 at about $800 \mathrm{~m}$ were mixed downwards and caused the strong increase of ultrafine particles observed at ground.

Assuming that the mean energy dissipation rate $\bar{\varepsilon}$ measured in the well-mixed layer by ACTOS during the last profile $\left(\bar{\varepsilon} \sim 10^{-2} \mathrm{~m}^{2} \mathrm{~s}^{-3}\right)$ is approximately the same at around 09:35 UTC for the height range from ground to $\sim 800 \mathrm{~m}$, we can estimate the time scale $\tau_{\text {mix }}$ which is needed to mix down the particles from $z=800 \mathrm{~m}$ to ground level by $\tau_{\text {mix }} \sim\left(\frac{z^{2}}{\bar{\varepsilon}}\right)^{1 / 3} \approx 6$ min. Due to this short time scale it is obvious that the rapid increase of ultrafine particles observed by NAIS is due to vertical mixing of the particles observed earlier by ACTOS in the residual layer, rather than new particle formation at ground level.

\section{Conclusions}

This study presents a unique combination of in-situ measurements with high temporal and spatial resolution at heights up to $1800 \mathrm{~m}$ covering meteorological and aerosol parameters, and continuous measurements of a lidar. While the in-situ measurement provides a very detailed snapshot of a certain measurement point in time and space, the lidar follows the development of the vertical structure of the backscatter signal above one location during the measurement period. Thus, the combination of both gives a more complete picture of the meteorological and aerosol stratification and may help to understand aerosol transport and formation processes.

The observations show the occurrence of ultrafine aerosol particles $(<20 \mathrm{~nm})$ within distinct layers inside the residual layer. These layers showed only slight differences of mean thermodynamic and dynamic parameters compared to the surrounding regions but were characterized by increased turbulence.

From our in-situ and remote sensing observations we can conclude that two circumstances might have played a role in this new-particle formation process in patchy layers: i) turbulent layers were responsible for creating favorable thermodynamic conditions (e.g., supersaturation of precursor gases due to non-linear mixing), ii) layers of increased aerosol concentration in the accumulation mode as observed by lidar limited NPF due to the larger particle surface area serving as a sink for ultrafine particles.

The corresponding air masses were of continentally polluted origin which is typically not the ideal environment for new particle formation due to a high available particle surface concentration. However, maybe the available concentration of condensable gases is high enough to enable new particle formation under more polluted conditions. But new particle formation has been observed also in heavily polluted environments, such as Beijing (Wu et al., 2007) and Mexico City (Dunn et al., 2004), therefore it should be realistic also under polluted conditions in Central Europe.

Particle measurements at ground level show a rapid increase of ultrafine particles just at the time when the wellmixed layer ranges from ground up to NSD800 $\mathrm{m}$ which corresponds to the height were the enhanced number concentration of ultrafine particles was found. Thus, it is very likely that these particles observed at the ground were formed at higher altitudes and mixed downwards. These observations have consequences for the interpretation of many earlier published ground-based observations of new particle formation through specific inclusion of measurements in the vertical dimension and boundary layer development. Without the airborne in-situ measurements and remote sensing, the observations at ground level could lead to a misinterpretation of location and processes causing the increase in ultrafine particles. 
The combination of ground-based, remote sensing (lidar) and airborne in-situ measurements with high spatial resolution clearly indicate a step forward to understanding the complex interaction between boundary layer dynamics, turbulence, and new particle formation. However, the nucleation process itself seems still an unsolved issue since precursor gas measurements are still missing in this context. In the future it would be interesting to have simultaneous, vertically resolved aerosol, chemical, and turbulence measurements within the boundary layer.

Acknowledgements. The authors thank all those people from KNMI which were involved in the IMPACT campaign for organization and all kinds of support before, during, and after the intensive campaign. Many thanks also to the helicopter companies rotorflug and HeliHolland and the pilots Alwin Vollmer, Jan Nienhaus, and Karel Wiegman. Furthermore, we thank to Dieter Schell and Christoph Klaus from the enviscope $\mathrm{GmbH}$ for their technical support during the campaign. The measurement campaign and data evaluation for this paper were conducted within the European Integrated project on Aerosol Cloud Climate and Air Quality Interactions (EUCAARI), coordinated by the University of Helsinki, Finland. The authors gratefully acknowledge the NOAA Air Resources Laboratory (ARL) for the provision of the HYSPLIT transport and dispersion model and the READY website (http://www.arl.noaa.gov/ready.html) used in this publication.

Edited by: V.-M. Kerminen

\section{References}

Asmi, E., M. Sipilä, H. E. Manninen, J. Vanhanen, K. Lehtipalo, S. Gagne, K. Neitola, A. Mirme, S. Mirme, E. Tamm, J. Uin, K. Komsaare, M. Attoui, and M. Kulmala: Results of the first air ion spectrometer calibration and intercomparison workshop, Atmos. Chem. Phys., 9, 141154, 2009

Apituley, A., Wilson, K. M., Potma, C., de Graaf, M., and Volten, H.: Performance Assessment and Application of Caeli - A high-performance Raman lidar for diurnal profiling of Water Vapour, Aerosols and Clouds. In: Proceedings of the 8th International Symposium on Tropospheric Profiling: Integration of Needs, Technologies and Applications (ISTP 2009), ISBN 97890-6960-233-2, 18-23 October 2009, Delft, The Netherlands, 2009.

Bigg, E. K.: A mechanism for the formation of new particles in the atmosphere, Atmos. Res., 43, 129-137, 1997.

Draxler, R. R. and Rolph, G. D.: HYSPLIT (Hybrid Single-Particle Lagrangian Integrated Trajectory) Model access via NOAA ARL READY Website (http://www.arl.noaa.gov/ready/hysplit4.html), NOAA Air Resources Laboratory, Silver Spring, MD, USA, 2003.

Dunn, M. J., Jimenez, J.-L., Baumgardner, D., Castro, T., McMurry, P. H., and Smith, J. N.: Measurements of Mexico City nanoparticle size distributions: Observations of new particle formation and growth., Geophys. Res. Lett., 31, L10102, doi:10.1029/2004GL019483, 2004.

Kavouras, I., and Stephanou, E.: Direct evidence of atmospheric secondary organic aerosol formation in forest atmosphere through heteromolecular nucleation, Environ. Sci. Technol., 36, 5083-5091, 2002.

Komppula, M., Lihavainen, H., Hatakka, J., Paatero, J., Aalto, P., Kulmala, M. and Viisanen, Y.: Observations of new particle formation and size distributions at two different heights and surroundings in subarctic area in northern Finland, J. Geophys. Res., 108, 4295, doi:10.1029/2002JD002939, 2003.

Kuang, C., McMurry, P. H., and McCormick, A. V.: Determination of cloud condensation nuclei production from measured new particle formation events. Geophys. Res. Lett. 36, L09822, doi:10.1029/2009GL037584, 2009.

Kulmala, M., Pirjola, L., and Mäkelä, J. M.: Stable sulphate clusters as a source of new atmospheric particles, Nature, 404, 66-69, 2000.

Kulmala, M., Dal Maso, M., Mäkelä, J. M., Pirjola,L., Väkevä, M., Aalto, P., Miikkulainen, P., Hämeri, K., and O'Dowd, C. D.: On the formation, growth and composition of nucleation mode particles, Tellus, 53B, 479-490, 2001.

Kulmala, M., Vehkamäki, H., Petäjä, T., Dal Maso, M., Lauri, A., Kerminen, V.-M., Birmili, W., and McMurry, P. H.: Formation and growth rates of ultrafine atmospheric particles: a review of observations, J. Aerosol Sci., 35, 143-176, 2004.

Kulmala, M., Asmi, A., Lappalainen, H. K., Carslaw, K. S., Pöschl, U., Baltensperger, U., Hov, Ø., Brenquier, J.-L., Pandis, S. N., Facchini, M. C., Hansson, H.-C., Wiedensohler, A., and O'Dowd, C. D.: Introduction: European Integrated project on Aerosol Cloud Climate and Air Quality interactions (EUCAARI) - integrating aerosol research from nano to global scales, Atmos. Chem. Phys., 9, 2825-2841, 2009, http://www.atmos-chem-phys.net/9/2825/2009/.

Kulmala, M., Riipinen, I., Sipilä, M., Manninen, H., Petäjä, T., Junninen H., Dal Maso, M., Mordas, G., Mirme, A., Vana, M., Hirsikko, A., Laakso, L., Harrison, R. M., Hanson, I., Leung, C., Lehtinen, K. E. J., and Kerminen, V.-M.: Towards direct measurement of atmospheric nucleation, Science, 318, 89-92, doi:10.1126/science.1144124, 2007.

Laaksonen, A., Hamed, A., Joutsensaari, J., Hiltunen, L., Cavalli, F., Junkermann, W., Asmi, A., Fuzzi, S. and Facchini, M.C. Cloud condensation nucleus production from nucleation events at a highly polluted region., Geophys. Res. Lett., 32, L06812, doi:10.1029/2004GL022092, 2005.

Manninen, H.E., Petäjä, T., Asmi, E., Riipinen, I., Nieminen, T., Mikkilä, J., Hörrak, U., Mirme, A., Mirme, S., Laakso, L., Kerminen, V.-M., and Kulmala, M.: Long-term field measurements of charged and neutral clusters using Neutral cluster and Air Ion Spectrometer (NAIS). Boreal Env. Res. 14, 591-605, 2009.

Marti, J. R. Weber, P.H. McMurry, F. Eisele, D. Tanner, and A. Jefferson, New particle formation at the remote continental site: Assessing the contribution on $\mathrm{SO}_{2}$ and organic precursors, J. Geophys. Res., 102, 6331-6340, doi:10.1029/96JD02552, 1997.

Mirme, A., Tamm, A., Mordas, G., Vana, M., Uin, J., Mirme, S., Bernotas, T., Laakso, L., Hirsikko, A., and Kulmala, M. A Wide-range multi-channel Air Ion Spectrometer. Boreal Env. Res., 12, 247-264, 2007.

Nilsson, E. D., Rannik, Ü., Kulmala, M., Buzorius, G., and O'Dowd, C. D.: Effects of continental boundary layer evolution, convection, turbulence and entrainment, on aerosol formation, Tellus, 53B, 441-461, 2001a.

O’Dowd, C., McFiggans,G., Creasey, D. J., Pirjola, L., Hoell, C., 
Smith, M. H., Allan,B. J., Plane, J. M. C., Heard, D. E., Lee, J. D., Pilling, M. J., and Kulmala, M.: On the photochemical production of new particles in the coastal boundary layer, Geophys. Res. Lett., 26, 1707-1710, 1999.

O’Dowd, C. D., Jimenez, J. L., Bahreini, R., Flagan, R. C., Seinfeld, J. H., Hämeri, K., Pirjola, L., Kulmala, M., Jennings, S. G., and Hoffmann, T.: Marine aerosol formation from biogenic iodine emissions, Nature, 417, 632-636, 2002.

Russchenberg, H., Bosveld, F., Swart, D., ten Brink, H., de Leeuw, G., Uijlenhoet, R., Arbresser-Rastburg, B., van der Marel, H., Lighthart, L., Boers, R., and Apituley, R.: Ground-Based Atmospheric Remote Sensing in the Netherlands: European Outlook. IEICE Transactions on Communications. 2005 June 2005; E88B(6), 2252-8, doi:10.1093/ietcom/e88-b.6.2252, 2005.

Siebert, H., Stratmann, F., and Wehner, B.: First observations of increased ultrafine particle number concentrations near the inversion of a continental planetary boundary layer and its relation to ground-based measurements, Geophys. Res. Lett., 31, L09102, doi:10.1029/2003GL019086, 2004.

Siebert, H., Franke, H., Lehmann, K., Maser, R., Saw, E. W., Schell, D., Shaw, R. A., and Wendisch, M.: Probing fine-scale dynamics and microphysics of clouds with helicopter-borne measurements, Bull. Am. Meteor. Soc., 87, 1727-1738, 2006 a.

Siebert, H., Lehmann, K., and Wendisch, M.: Observations of small scale turbulence and energy dissipation rates in the cloudy boundary layer, J. Atmos. Sci. 63, 1451-1466, 2006 b.

Siebert, H., Wehner, B., Hellmuth, O., Stratmann, F., Boy, M., and Kulmala, M.: New-Particle Formation in Connection with a Nocturnal Low-Level Jet: Observations and Modeling Results. Geophys. Res. Lett., 34(16), L16822, doi:10.1029/2007GL029891, 2007.

Spracklen, D. V., Carslaw, K. S., Kulmala, M., Kerminen, V.-M., Mann, G. W., and Sihto, S.-L.: The contribution of boundary layer nucleation events to total particle concentrations on regional and global scales, Atmos. Chem. Phys., 6, 5631-5648, 2006, http://www.atmos-chem-phys.net/6/5631/2006/.

Spracklen, D. V., Carslaw, K. S., Kulmala, M., Kerminen, V.-M., Sihto, S.-L., Riipinen, I., Merikanto, J., Mann, G. W., Chipperfield, M. P., Wiedensohler, A., Birmili, W., and Lihavainen, H.: Contribution of particle formation to global cloud condensation nuclei concentrations, Geophys. Res. Lett., 35, L06808, doi:10.1029/2007GL033038, 2008.
Stratmann, F., Siebert, H., Spindler, G., Wehner, B., Althausen, D., Heintzenberg, J., Hellmuth, O., Rinke, R., Schmieder, U., Seidel, C., Tuch, T., Uhrner, U., Wiedensohler, A., Wandinger, U., Wendisch, M., Schell, D., and Stohl, A.: New-particle formation events in a continental boundary layer: first results from the SATURN experiment, Atmos. Chem. Phys., 3, 1445-1459, 2003, http://www.atmos-chem-phys.net/3/1445/2003/.

Stanier, C. O., Khlystov, A. Y., and Pandis, S. N.: Nucleation events during the Pittsburgh Air Quality study: Description and relation to key meteorological, gas phase, and aerosol parameters, Aerosol Sci. Technol., 38, 253-264, 2004.

Stull, R. B.: An introduction to boundary layer meteorology, Kluwer Academic Publishers, Dordrecht, The Netherlands, 666 p, 1988.

Weber, R. J., Marti, J. J., McMurry, P. H., Eisele, F. L., Tanner, D. J., and Jefferson, A.: Measurements of new particle formation and ultrafine particle growth rates at a clean continental site, J. Geophys. Res., 102, 4375-4385, 1997.

Wehner, B., Siebert, H., Stratmann, F., Tuch, T., Wiedensohler, A., Petäjä, T., Dal Maso, M., and Kulmala, M.: Horizontal homogeneity and vertical extend of new particle formation events, Tellus, 59B, 362-371, 2007.

Wiedensohler, A., Covert, D. S., Swietlicki, E., Aalto, P., Heintzenberg, J., and Leck, C.: Occurrence of an ultrafine particle mode less than $20 \mathrm{~nm}$ in diameter in the marine boundary layer during Arctic summer and autumn, Tellus, 48B, 213-2226, 1996.

Wiedensohler, A., Cheng, Y. F., Nowak, A., Wehner, B., Achtert, P., Berghof, M., Birmili, W., Rose, D., Pöschl, U., Hu, M., Zhu, T., Takegawa, N., Kita, K., Kondo, Y., and Lou, S. R.: Rapid Particle Growth by Secondary Aerosol Formation to CCN - A Case Study for the Polluted Aerosol in North-Eastern China, J. Geophys. Res., 114, D00G08, doi:10.1029/2008JD010884, 2009.

Woo, K. S., Chen, D. R., Pui, D. Y. H., and McMurry, P. H.: Measurement of Atlanta Aerosol Size Distributions: Observation of ultrafine particle events, Aerosol Sci. Technol., 34, 75-87, 2001.

Wu, Z., Hu, M., Liu, S., Wehner, B., Bauer, S., Wiedensohler, A., Petäjä, T., Dal Maso, M., Kulmala, M.: New particle formation in the mega-city: Beijing, China, J. Geophys. Res., 112, D09209, doi:10.1029/2006JD007406, 2007.

Wyngaard, J. C.: Atmospheric turbulence, Annu. Rev. Fluid Mech., 24, 205-233, 1992. 